\title{
A CAUSA E AS POLÍTICAS DE DIREITOS HUMANOS NO BRASIL
}

\author{
Fabiano Engelmann* \\ Lígia Mori Madeira**
}

\begin{abstract}
Pretende-se analisar a emergência e consolidação da causa dos direitos humanos no Brasil nas últimas décadas. O argumento principal é que o movimento dos direitos humanos emerge, como em outros contextos da América latina, a partir da contestação do regime militar-autoritário e consolida-se a partir de marcos institucionais após a redemocratização do país. A análise do perfil das causas e dos trajetos dos principais líderes do movimento no Brasil permite afirmar que os direitos humanos transformam-se, ao longo da década de 90, em uma "causa de Estado". Um dos indicadores mais forte dessa transformação é a articulação entre os movimentos militantes e a burocracia governamental e a expansão de programas de direitos humanos principalmente nas regiões sul, sudeste e norte.
\end{abstract}

Palavras-chave: Brasil. Direitos Humanos. Ativismo. Políticas Públicas.

\section{INTRODUÇÃO}

A análise sociopolítica da construção da causa dos direitos humanos no espaço público brasileiro envolve um conjunto de dimensões inter-relacionadas. Pode-se mencionar como relevantes, em um primeiro momento, os efeitos de conjuntura favoráveis ao ativismo internacional ${ }^{1}$ e às estratégias de sobrevivência de grupos políticos frente ao regime militar. Em um segundo período, temos a proliferação do ativismo onde se destacam a defesa de apenados, grupos sociais minoritários e a proteção da infância. A agenda militante também passa a se ancorar fortemente nas duas últimas décadas em burocracias estatais especializadas

* Universidade Federal do Rio Grande do Sul. Instituto de Filosofia e Ciências Humanas. Departamento de Ciência Política. Av. Bento Gonçalves, 9500 - Prédio 43311. Campus do Vale. Cep: 91501-970. Porto Alegre - Rio Grande do Sul Brasil. Caixa Postal 15055. fabengel@gmail.com.

** Universidade Federal do Rio Grande do Sul. Instituto de Filosofia e Ciências Humanas. Departamento de Ciência Política.

Av. Bento Gonçalves, 9500 - Prédio 43311. Campus do Vale. Cep: 91501-970. Porto Alegre - Rio Grande do Sul Brasil. Caixa Postal 15055. ligiamorimadeira@gmail.com

${ }^{1}$ Sobre a emergência dos movimentos de direitos na América latina e as iniciativas de organizações americanas em direção ao sul, ver Dezalay \& Garth (2001). na promoção de políticas públicas de direitos humanos.

Este artigo pretende se fixar com mais detalhamento em duas dimensões. Em primeiro lugar, os fatores que circundam o aparecimento do ativismo em torno dos direitos humanos no Brasil como uma das estratégias de enfrentamento político e jurídico do regime militar. Aqui se busca contextualizar o fechamento da ordem jurídico-política que legitimou o poder das elites militares a partir de 64 e restringiu os grupos políticos. A emergência da causa dos direitos humanos aparece estreitamente relacionada a este contexto e coadunando-se com as trajetórias de ativismo de um grupo de advogados vinculados à Igreja Católica. A segunda dimensão enfoca a redefinição da agenda militante nas décadas de 90 e 2000 com a consolidação de estruturas institucionais que projetam os direitos humanos como uma "política de Estado" com variantes regionais. Descreve-se como esse processo deu origem, nos anos 1980, aos primeiros movimentos que reivindicavam mais nitidamente a promoção dos direitos humanos, desembocando nas estruturas institucionais que proliferam 
nas décadas de 90 e 2000. Ao longo da década de 90, há uma diversificação nas políticas de direitos humanos, o que fica evidenciado a partir da maior articulação entre movimentos militantes e a burocracia governamental, resultando na expansão regional de programas específicos ancorados na esfera estatal.

A continuidade das políticas específicas articuladas, assim como das iniciativas e dos movimentos ancorados fora da burocracia governamental são uma importante dimensão para a análise da consolidação política e simbólica dos direitos humanos no Brasil.

\section{CONTESTAÇÃO DO REGIME MILI- TAR E A EMERGÊNCIA DA CAUSA DOS DIREITOS HUMANOS}

\section{O estreitamento do espaço político e jurídi- co pelos militares}

A edificação da "ordem jurídica" do regime militar inicia-se logo após a deposição do presidente civil João Goulart em 1964, com a edição dos Atos Institucionais que visam construir a legitimidade jurídica das ações políticas dos militares. A sucessiva edição de atos institucionais e da Constituição de 1967 é orientaم da pela Doutrina de Segurança Nacional, consㄱ. truída para enquadrar potenciais inimigos do Фं Regime. Esse "efeito de instituição" do regime 这 atinge o espaço judicial enquanto garantidor de direitos políticos através de dois eixos fun-

\& Segurança Nacional às demais garantias dessas $\stackrel{\infty}{N}$ funções. Em outro sentido, fortalece e redefine $\vec{i}$ as funções da Justiça Militar, que se torna um espaço de julgamento dos "crimes políticos". 2 O Ato Institucional n. 5 (AI-5), promulgado no final do ano de 1968, marca o endurecimento

${ }^{2}$ Sobre a redefinição institucional da Justiça Militar a partir da Lei de Segurança Nacional, ver Pereira (2005) e sobre os processos por crime político ver relatório Brasil: nunca mais, originalmente publicado em 1985. do regime militar e a diminuição do espaço político e jurídico para parte das elites políticas civis. O fechamento do Congresso Nacional, a proibição de associações, a restrição da liberdade de imprensa e intensificação à perseguição de adversários têm por consequência a reconversão das causas políticas e métodos de "fazer política".

No espaço judicial, a intervenção no Supremo Tribunal Federal (STF) em janeiro de 1969, consequência do AI-5, tem um conteúdo simbólico extremamente forte e que, em alguma medida, pode ser tomado como marco da reformulação das lutas jurídicas contra os militares. Durante o período 1964-1968, o STF concedeu habeas corpus às demandas propostas pelos advogados dos presos políticos pelo regime, tendo prevalecido as condições institucionais de ação previstas na Constituição de 1946, último marco institucional democrático anterior ao regime militar. Entretanto, já com a edição do AI-2 em 1965, a intervenção dos militares na cúpula do Judiciário brasileiro é iniciada, sendo ampliado o número dos seus integrantes de 11 ministros para 16. Com base nesta possibilidade, Castello Branco, o primeiro presidente do regime militar, nomearia oito ministros do STF até o final do seu mandato em 1967, e seu sucessor, Costa e Silva, nomearia outros quatro novos integrantes. Em janeiro de 1969, poucos meses antes do final do mandato de Costa e Silva, três ministros do STF são aposentados compulsoriamente. Tal retaliação, destinada aos ministros Victor Nunes Leal, Hermes Lima e Evandro Lins e Silva, deu-se porque estes, em votação no STF, haviam se pronunciado contra a cassação do Deputado Federal Marcio Moreira Alves, que teve o mandato revogado por atacar o governo militar na Câmara Federal. Em solidariedade aos ministros aposentados, o presidente do STF, Antônio Gonçalves Oliveira, e o ministro mais antigo do Tribunal, Lafayette de Andrada, pediram aposentadoria.

Os três ministros aposentados fazem parte de uma geração de juristas-políticos que, 
no período anterior ao regime, atuou alinhada com forças políticas opostas aos militares golpistas. São juristas e políticos em final de carreira. Evandro Lins e Silva, fundador do Partido Socialista Brasileiro em 1947, ocupou diversos postos políticos, entre os quais, o de Ministro de Relações Exteriores do presidente civil deposto em 1964, João Goulart. Já Victor Nunes Leal, jurista e ensaísta político, ocupou o cargo de Chefe da Casa Civil do governo do presidente Juscelino Kubitschek. Finalmente, Hermes Lima fora primeiro-ministro durante o curto período de parlamentarismo atravessado pelo Brasil, além de aliado do presidente deposto João Goulart.

Em outro sentido, o governo autoritário investe no fortalecimento da Justiça Militar, criada ainda durante o período colonial em 1808 e utilizada pelo aparelho de repressão política montado no Estado Novo de Getúlio Vargas em 1937. O Ato Institucional n. 2 modifica o número de juízes militares de 11 para 16, com a maioria nomeada pelo presidente Castelo Branco, como já mencionado. Conforme Pereira (2005), a instância superior da Justiça Militar, o Superior Tribunal Militar, afirma-se como um espaço de discussão do sentido da Lei de Segurança Nacional e com capacidade para centralizar os processos envolvendo "crimes políticos".

Os efeitos da construção institucional do regime militar com a restrição do espaço político encolhem o campo estatal para as elites civis contrárias ao regime e contribuem para a emergência da "causa dos direitos humanos" através da articulação fora do espaço estatal de grupos políticos, religiosos e de juristas em torno da contestação do regime. A causa coletiva, que advém das mobilizações contra o regime militar, prossegue após a transição, sendo redefinida de diversas maneiras. Seja em direção à defesa dos direitos dos presos comuns, ou de movimentos sociais, como os trabalhadores sem-terra, seja nas mobilizações pela revisão da Lei da Anistia na década de 2000, ou, ainda, nos processos judiciais individuais e coletivos propostos por organizações ou famílias de vítimas da repressão militar, visando indenizações e o reconhecimento da culpabilidade do Estado.

\section{A causa dos direitos humanos na década de 1970: a recuperação do direito à política}

A emergência da causa dos direitos humanos no Brasil dá-se a partir da década de 1970, no cenário da articulação de grupos políticos em torno das reivindicações pelo restabelecimento de direitos. Dentre os vários segmentos envolvidos com a causa, destacam-se as diferentes organizações católicas. ${ }^{3}$ Nos momentos que antecederam o movimento militar de 1964, bem como na sua consolidação, setores do catolicismo promoveram uma sucessão de marchas, manifestando apoio ao novo regime. Com a realização do Concílio Vaticano II, é iniciado, no interior da Igreja Católica latino-americana, um ciclo no qual a preocupação com as causas sociais ganharia destaque. A repercussão mais clara dessa orientação no Brasil é a Comissão de Justiça e Paz, fundada em 1969, que se afirma como um dos marcos da articulação da causa dos direitos humanos no Brasil. A Comissão foi criada como uma subseção da comissão de Roma, visando, assim, escapar da repressão política do regime militar. Em 1972, é criada uma seção no Estado de São Paulo e, em 1973, no Estado do Rio Grande do Sul. O envolvimento de setores da Igreja com as famílias de presos políticos contribuiu para a articulação, em São Paulo, de um núcleo de defesa jurídica dos perseguidos pelo regime.

Essa articulação favoreceu a entrada em cena de um grupo de advogados com atuação política prévia ao golpe militar, que voltam à cena pública engajados na defesa de presos políticos, projetando-se como mediadores junto a ${ }^{3}$ Coordenadoria Ecumênica de Serviço (CESE), Comissão Brasileira de Justiça e Paz, Comissão de Justiça e Paz da Arquidiocese de São Paulo, Conselho Indigenista Missionário (CIMI), Centros de Educação Popular, Comunidades Eclesiais de Base, Juventude Operária Católica (JOC), Juventude Universitária Católica (JUC), Pastorais. 
redes internacionais de ativistas, assim como, após o fim do regime militar, para postos de poder político e direção de organizações identificadas ao movimento de direitos humanos. Este grupo, formado, predominantemente, de advogados católicos reunidos em torno da Comissão de Justiça e Paz, pode ser identificado a uma geração de juristas paulistas que teve suas carreiras políticas abreviadas pelo golpe militar. Diferentemente de uma primeira geração em fim de carreira, à qual pertencem os ministros aposentados compulsoriamente do STF - todos cariocas e formados em direito entre 1917-1935 na faculdade de direito do Rio de Janeiro - esta segunda geração de juristas, ancorada na advocacia, terá um papel mais ativo após o final do regime militar, o que fica evidenciado pela comparação das trajetórias políticas. No Quadro 1, são destacados os trajetos de quatro casos representativos deste da Igreja Católica e tem um papel importante na institucionalização da causa dos direitos humanos ao longo das últimas décadas. Tanto na participação militante, através da defesa de presos políticos e nas tomadas de posição pública de contestação ao regime militar, quanto na batalha intelectual, com a publicação de textos e livros com doutrinas jurídicas que enfatizam os direitos humanos e repercutem na formatação institucional dos direitos e garantias individuais presentes na Constituição de 1988. ${ }^{4}$ Em sua maioria, o grupo é contemporâneo de estudos de direito na USP, formados entre 1954 e 1959 e com percursos comuns como professores da USP e atuação na advocacia. Ocupam, também, postos públicos importantes na década de 90, no momento em que começam a ser construídas as estruturas burocráticas que promovem a causa dos direitos humanos como uma "causa de Estado".

Quadro 1 - Trajetos representativos de juristas vinculados à Comissão de Justiça e Paz

\begin{tabular}{|c|c|c|c|c|}
\hline Nome & Ano grad & Postos políticos & Postos em organizações & Informações gerais \\
\hline Hélio Bicudo & 1947 & $\begin{array}{l}\text { 1963: Ministro Interino da Fazenda } \\
\text { no Governo João Goulart. } \\
\text { 1989/90: Secretário dos Negócios } \\
\text { Jurídicos do Município de São Paulo. } \\
\text { 1990/98: Deputado Federal-PT, por } \\
\text { dois mandatos. } \\
\text { 2001/04: Vice-Prefeito de São Paulo - PT }\end{array}$ & \begin{tabular}{|l|} 
1972: Membro-fundador da Comissão \\
Justiça e Paz de São Paulo (CJP-SP) \\
2000: Presidente da Comissão \\
Interamericana de Direitos Humanos (CIDH). \\
2003: Cria a Fundação Interamericana de \\
Defesa aos Direitos Humanos (FidDH).
\end{tabular} & $\begin{array}{l}\text { Promotor público, autor do livro-denúncia } \\
\text { Meu depoimento sobre o “esquadrão da } \\
\text { morte” (de 1974), participou da delegação } \\
\text { brasileira enviada à } 2^{a} \text { Conferência Mundial } \\
\text { dos Direitos Humanos realizada pela ONU, } \\
\text { na Áustria, em } 1993 .\end{array}$ \\
\hline $\begin{array}{l}\text { Dalmo de } \\
\text { Abreu Dallari }\end{array}$ & 1957 & $\begin{array}{l}\text { 1990/92: Secretário dos } \\
\text { Negócios Jurídicos da } \\
\text { Prefeitura de São Paulo. }\end{array}$ & $\begin{array}{l}\text { 1972: Membro-fundador da Comissão } \\
\text { Justiça e Paz de São Paulo (CJP-SP) } \\
\text { 1975/78: Presidente da CJP-SP) } \\
\text { 1996: Nomeado professor catedrático da } \\
\text { Cátedra Educação para a Paz, Direitos } \\
\text { Humanos e Democracia e Tolerância, } \\
\text { da UNESCO. } \\
\text { 1992/2001: Vice-presidente da Comissão } \\
\text { Internacional de Juristas (ONG com } \\
\text { estatuto consultivo junto à ONU). }\end{array}$ & $\begin{array}{l}\text { Professor universitário da USP, autor de } \\
\text { diversos livros sobre teoria do estado e } \\
\text { estudos sobre direitos humanos publicados } \\
\text { desde a década de } 1970 .\end{array}$ \\
\hline $\begin{array}{l}\text { Fábio Konder } \\
\text { Comparatto }\end{array}$ & 1959 & & $\begin{array}{l}\text { 1972: Membro-fundador da Comissão } \\
\text { Justiça e Paz de São Paulo (CJP-SP) } \\
\text { Década de 1980: Fundador e diretor da } \\
\text { Escola de Governo. }\end{array}$ & $\begin{array}{l}\text { Professor universitário da USP, doutor } \\
\text { Paris I (1963). Em 1992, promove a ação de } \\
\text { impeachment de Fernando Collor de Mello. } \\
\text { Promove ações populares contra as } \\
\text { privatizaçôes. }\end{array}$ \\
\hline $\begin{array}{l}\text { José Carlos } \\
\text { Dias }\end{array}$ & 1963 & $\begin{array}{l}\text { 1983/86: Secretário da Justiça do Estado } \\
\text { de São Paulo 1999/2000: Ministro da } \\
\text { Justiça no governo Fernando Henrique } \\
\text { Cardoso. }\end{array}$ & $\begin{array}{l}\text { 1972: Membro-fundador da Comissão } \\
\text { Justiça e Paz de São Paulo (CJP-SP) } \\
\text { 1978/81: Presidente da CJP-SP } \\
\text { 1982: Fundador da Comissão Teotônio } \\
\text { Vilela de Direitos do Homem. } \\
\text { 2000: Fundou o Instituto de Defesa do } \\
\text { Direito de Defesa - IDDD. }\end{array}$ & Advogado criminalista. \\
\hline \multicolumn{5}{|c|}{ Fonte: Base de Dados do Projeto Intérpretes da Constituição: porta-vozes de políticas: juristas e ordem política brasileira, CNPq. } \\
\hline $\begin{array}{l}\text { grupo, He } \\
\text { Fábio Kor } \\
\text { Est } \\
\text { como fur }\end{array}$ & $\begin{array}{l}\text { grup } \\
\text { lador }\end{array}$ & $\begin{array}{l}\text { cudo, Dalmo de Abreu Da } \\
\text { omparatto e José Carlos Di } \\
\text { po de advogados partic } \\
\text { da Comissão de Justiça }\end{array}$ & 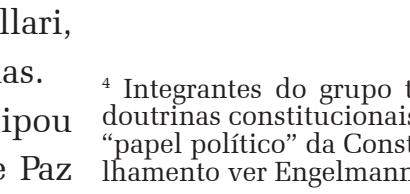 & $\begin{array}{l}\text { têm papel ativo na produção de } \\
\text { is que repercutem na discussão do } \\
\text { tituição de } 1988 \text {. Para maior deta- } \\
\text { n (2006 ) e Engelmann (2016b ). }\end{array}$ \\
\hline
\end{tabular}




\section{OS DIREITOS HUMANOS COMO POLÍTICA DE ESTADO}

\section{Dos anos 1980 aos anos 2000: movimentos em direção ao poder e novas agendas}

Já no final dos anos 70, ocorre uma progressiva autonomização da pauta dos direitos humanos em relação às organizações católicas. A partir desse momento, a causa atinge uma perspectiva mais ampla, voltada à preservação de direitos coletivos, sendo as áreas prioritárias de ação, a violência policial, o saneamento básico, as creches, a orientação trabalhista e a organização de grupos de saúde (Vieira, 2005, p. 49). É desta fase a formação do Grupo Tortura Nunca Mais, em 1985, fundado por ex-presos políticos, familiares de mortos e desaparecidos ao longo do regime militar. Durante a transição para a redemocratização, os movimentos lutaram pela incorporação de direitos na nova Constituição Federal, estimulando a institucionalização de entidades da sociedade civil. Nessa fase, “[...] parte dos antigos militantes ou lideranças dos movimentos passaram a participar da esfera governamental [...]" implicando um "refluxo dos movimentos contestatórios” (Scherer-Warren, 2008, p. 12).

Já ao longo dos anos 1980, os ativistas de direitos humanos encontraram vários canais de articulação com o Estado brasileiro, seja através da montagem de Comissões de Direitos Humanos no âmbito dos poderes legislativos, seja pela fundação do Movimento Nacional de Direitos Humanos (MNDH) em 1982. Se a causa de direitos humanos no Brasil foi constituída ainda sob a égide da ditadura militar, tendo como marca a luta contra o regime autoritário e suas frequentes violações às garantias fundamentais, é no retorno ao regime democrático que assume, progressivamente, um viés de “causa de Estado". No entanto, o processo de institucionalização não implica uma legitimação social no mesmo ritmo. Ao longo do regime militar, as batalhas por direitos tinham entre seus centros a denúncia da tortura e assas- sinatos de dissidentes. No período posterior, no entanto, com a eclosão, durante o processo democratizante, de altas taxas de criminalidade, emerge uma visão conservadora que se contrapõe à diminuição da função repressora do Estado. Conforme acentuam Paulo Sergio Pinheiro e Paulo Mesquita Neto (1997, p. 121):

Nos anos 60 e 70 a violência arbitrária do Estado e o desrespeito às garantias fundamentais fez com que indivíduos e grupos se voltassem contra o regime autoritário em nome da defesa dos direitos humanos. As primeiras comissões de direitos humanos foram instituídas a partir da década de $70 \mathrm{e}$ chamaram a atenção para a tortura e os assassinatos de dissidentes e presos políticos revelando as condições gritantes das prisões brasileiras. Nos anos 80 e 90, entretanto, o aumento da criminalidade e da insegurança, agora sob o regime democrático levou indivíduos e coletividades a se voltarem contra a defesa dos direitos humanos, os quais alegavam que tais direitos serviam mais aos criminosos e aos delinquentes do que às vítimas.

Adorno (2010) também aponta para a demora da legitimação da agenda dos direitos humanos no Brasil, justamente em função de que "[...] temas de direitos humanos suscitavam reações depreciativas frequentemente associadas pela opinião pública, à defesa dos direitos de bandidos, à utopia de militantes que imaginavam uma sociedade despida de violência ou ainda à sede de vingança por parte de quem havia sido perseguido durante a ditadura militar" (Adorno, 2010, p. 5). Apesar de a Constituição Federal de 1988 afirmar-se no marco legal originário para tal processo, é em 1996, com a edição do I Plano Nacional de Direitos Humanos (PNDH), e no ano seguinte, com a criação da Secretaria Nacional de Direitos Humanos no Ministério da Justiça, durante o primeiro mandato do Presidente Fernando Henrique Cardoso, que a temática assume, efetivamente, relevância como "assunto de Estado". Conforme Pinheiro \& Mesquita Neto (1997), o plano nacional foi elaborado incorporando contribuições de organizações não governamentais e contemplando um ciclo de se- 
minários regionais em seis capitais brasileiras, constituindo-se no primeiro programa de proteção aos direitos humanos na América Latina.

O conceito de direitos humanos assumido pelo primeiro PNDH reconhece o papel e a obrigação do Estado como órgão promotor dos direitos humanos, bem como a universalidade e indivisibilidade de tais direitos. A adoção de um conceito largo de direitos humanos, que engloba direitos civis e políticos, mas, também, econômicos, sociais e culturais - pelo governo brasileiro - reforça perspectivas defendidas por organismos internacionais. (Pinheiro; Mesquita Neto, 1997, p. 123). Não houve referência aos direitos à livre orientação sexual e identidades de gênero, tendo sido privilegiada a preocupação com a redução da violência e do crime através de medidas ligadas à segurança pública. Dentre essas medidas, destacam-se a transferência de julgamento de crimes dolosos contra a vida cometidos por policiais militares para a justiça comum, a tipificação do crime de tortura, a criminalização do porte ilegal de armas e a criação do Estatuto dos Refugiados.

\section{"Estatização" da causa, planos e (re) con- versão dos ativistas} Direitos Humanos em 1997 no âmbito do Ministério da Justiça teve por propósito a coordenação das ações de execução do Programa Nacional de Direitos Humanos-PNDH. Como parte da construção das estruturas governamentais, essa iniciativa foi imprescindível para a implementação da política de direitos humanos no Brasil. Ainda durante o governo do presidente Fernando Henrique Cardoso, no seu segundo mandato, em 2002, é lançado o II PNDH, resultado da revisão e do aperfeiçoamento do primeiro programa e incorporando as recomendações da IV Conferência Nacional de Direitos Humanos, ocorrida em 1999 (Adorno, 2010, p. 10).

O conteúdo do segundo Programa refor- ça as orientações do primeiro e amplia os direitos a serem protegidos, especialmente mencionando direitos de identidade de gênero, enfatizando a violência intrafamiliar, o combate ao trabalho infantil e a luta pela inclusão de pessoas portadoras de deficiências. Conforme Adorno (2010), enquanto o I PNDH privilegiou os direitos civis e políticos, o II PNDH avança na proteção dos direitos sociais, econômicos e culturais. Esse avanço, detalhado pelo autor, inclui a "[...] proteção de direitos à educação, à saúde, à previdência e à assistência social, à saúde mental, aos dependentes químicos e portadores de HIV/AIDS, ao trabalho, ao acesso à terra, à moradia, ao meio ambiente saudável, à alimentação, à cultura e ao lazer" (Adorno, 2010, p. 12). Outro foco é a inclusão de medidas protetivas dos afrodescendentes, através de políticas de ações afirmativas.

Em $1^{\circ}$ de janeiro de 1999, a SNDH foi transformada em Secretaria de Estado dos Direitos Humanos - SEDH, com assento nas reuniões ministeriais. Dentre os secretários da SEDH, durante os mandatos de Fernando Henrique Cardoso, estiveram José Gregori (1997/2000), (2000/2001) e Paulo Sérgio Pinheiro (2001/ 2003). José Gregori e Paulo Sérgio Pinheiro também se destacaram em outras funções, o primeiro como Ministro da Justiça (2000/2001) e segundo como redator dos PNDH I e II. Além deles, José Carlos Dias também obteve destaque nas políticas estatais de direitos humanos quando Ministro da Justiça entre os anos 1999 e 2000. A análise dos trajetos dessas lideranças políticas e intelectuais indica se tratar de um grupo de advogados que participou da resistência ao regime militar e que, mesmo ocupando postos no governo, adquire relativa autonomia frente à coalizão governamental:

\footnotetext{
A bem da verdade, os governos civis pós-redemocratização deram início à incorporação de direitos humanos nas políticas governamentais. Todavia, foi no governo FHC que o tema entrou definitivamente para a agenda política nacional, em parte graças a uma conjuntura internacional favorável, em parte devido à presença mais destacada no governo de li-
} 
deranças reconhecidas e identificadas com direitos humanos, como os ministros José Gregori e Paulo Sérgio Pinheiro. Ainda assim, é bom lembrar, não se pode dizer que a composição de forças e alianças de sustentação do governo FHC fosse inteiramente simpática à agenda, sobretudo quando em pauta estavam iniciativas que visassem exercer férreo controle civil sobre as forças policiais militares, ou que pretendessem reparação diante das graves violações de direitos humanos ocorridas no curso da ditadura militar. (Adorno, 2010, p. 9).

Com a ascensão de Luís Inácio Lula da Silva e do PT ao governo, inicia uma nova fase no processo de institucionalização dos direitos humanos no Brasil. Se, por um lado, há continuidades apontadas pela manutenção da preocupação em implementar direitos e garantias previstas constitucionalmente, por outro, percebem-se mudanças na expansão dos direitos a serem protegidos a partir da elaboração do III Plano Nacional de Direitos Humanos, como exposto mais adiante. Outro fator que chama a atenção é a alteração do perfil dos dirigentes em postos-chave nas burocracias relacionadas à causa, que deixam de ser originários das áreas jurídicas, assumindo perfis com diferentes formações, cuja característica unificadora é a militância política vinculada ao Partido dos Trabalhadores (PT).

Durante os mandatos dos presidentes Luis Inácio Lula da Silva e Dilma Rouseff (2010 a 2013), passaram pela Secretaria, Nilmário Miranda, Mário Mamede Filho, Paulo de Tarso Vannuchi e Maria do Rosário. Com diferentes formações, os secretários destacam-se pelo militantismo anterior à chegada ao governo e, também, com passagens pelos poderes legislativos. A trajetória mais marcante na luta contra as violações de direitos humanos nessa nova fase é, sem dúvida, a do ex-ministro Vannuchi, cuja atuação na formulação do III PNDH marcou a história recente da consolidação dos direitos humanos no Brasil.

Os dados dos trajetos políticos e de participação em organizações e comissões nacionais e internacionais de direitos humanos indicam a relativa autonomização da agenda dos movimentos em relação à esfera da política representativa e partidária. Independente da trajetória de exercício de mandato parlamentar e vínculos partidários, os dirigentes da Secretaria possuem, ao menos até 2011, uma forte imbricação com o espaço do militantismo, incluindo organizações de resistência ao regime militar anteriores aos organismos de promoção dos direitos humanos (Anexo I).

O III PNDH amplia o rol de direitos ao incorporar demandas oriundas das conferências ocorridas ao longo do período da década de 2000, percebe-se a continuidade e o aprofundamento da preocupação com direitos civis e sociais. A inovação do plano aparece no resguardo das liberdades individuais ao propor a descriminalização do aborto, a união civil de pessoas do mesmo sexo, o direito de adoção por casais homoafetivos e a efetivação da laicidade do Estado. Mas é nas feridas abertas pelo regime autoritário, com a proposição da Comissão Nacional de Verdade para investigar

Quadro 2 - Temas recorrentes Revistas de direitos humanos

- Direitos humanos e cidadania

- Desenvolvimento do ensino e da pesquisa sobre Direitos Humanos.

- Educação para os Direitos Humanos; Criança e Adolescente;

- Desemprego; Segurança Pública; Reforma Penitenciária; Reforma Agrária; Relações Raciais e Combate à Impunidade.

- Constituir instrumento de veiculação de trabalhos científicos e doutrinários relacionados à Positivação e Concretização Jurídica dos Direitos Fundamentai e dos Direitos Humanos.

- Direitos Humanos, Ética e Cidadania.

- Integrar profissionais do hemisfério sul e ampliar sua voz perante a ONU

- Saúde como direito fundamental

- História, filosofia, comunicação social e direitos humanos.

- Educação em direitos humanos

- Combate à tortura.

- Direito das mulheres

Fonte: Base de Dados do Projeto Intérpretes da Constituição: porta-vozes de políticas: juristas e ordem política brasileira, CNPq. Ver quadro completo das revistas no Anexo II. 
as violações de direitos ao longo do regime militar, que o plano suscitou críticas mais duras dos setores tradicionais da sociedade.

Indicativo complementar do perfil de demandas abrigadas no guarda-chuva das definições de direitos humanos pode ser obtido ao se analisar o amplo leque de revistas especializadas que proliferam ao longo da década de 2000. Articuladas por associações, observatórios e, também, por programas de pós-graduação que se formam no espaço acadêmico em torno das questões relacionadas à temática.

\section{Políticas e programas de direitos humanos no Brasil: arranjos entre as entidades sub- nacionais}

Tendo em vista o panorama descrito sobre a institucionalização de políticas de direitos humanos pelo governo federal, o objetivo desta seção é a análise das ações em curso entre as entidades federais e entes subnacionais estados, municípios e organismos da sociedade civil - buscando verificar quais os tipos de programas e políticas de direitos humanos implementados, quais as temáticas mais encontradas e a relação entre o perfil das temáticas e as regiões do país. Os dados foram construídos n a partir dos convênios da União federal no PorS tal da Transparência, selecionados pelo termo هं direitos humanos. A União realizou 405 con这 vênios com entes subnacionais e entidades da sociedade civil entre os anos de 2009 e 2012.

\section{Região Sudeste}

Os convênios na região Sudeste têm como órgãos concedentes prioritários a Secretaria Especial de Direitos Humanos - SEDH, o Fundo Nacional da Criança e do Adolescente, a Secretaria Especial de Políticas para as $\mathrm{Mu}-$ lheres - SENASP e a Secretaria Especial de
Políticas para a Promoção da Igualdade Racial - SEPPIR. Entre as entidades financiadas pelos convênios há uma variação significativa nos estados. Enquanto o estado de São Paulo tem nas entidades da sociedade civil as maiores promotoras de ações, restando alguns convênios com prefeituras, o estado do Rio de Janeiro tem uma clara divisão entre convênios promovidos por organismos da sociedade civil, por secretarias estaduais, geralmente de assistência social e direitos humanos e prefeituras. Já no caso de Minas Gerais, novamente, a maior incidência é de convênios promovidos pela sociedade civil. Enquanto no Espírito Santo são as secretarias estaduais quem mais promovem ações.

As ações de promoção a direitos humanos financiadas pela SEDH, pela SEPM e SEPPIR na região sudeste reproduzem os eixos de atuação nacional. As ações financiadas pela SENASP também têm essa característica, promovendo prevenção, capacitação de agentes e implementando programas voltados ao público em vulnerabilidade criminal. Apesar da importância desses convênios, seu número é muito inferior aos promovidos por outras Secretarias, como a SEDH e a SEPM.

No caso da implementação de políticas federais, encontramos o Programa Nacional de Enfrentamento à Violência Sexual, o Programa de Erradicação do Tráfico de Pessoas, o Sistema de Garantias de Direitos das Crianças e Adolescentes, o Plano Nacional de Políticas para as Mulheres, os Centros de Referência em Direitos Humanos e os programas da Política de Segurança Alimentar promovida pelo Ministério do Desenvolvimento Social e combate à Fome (MDS).

A análise dos convênios na região Sudeste permite inferir que regiões com tradição em políticas e programas de direitos humanos desenvolvem arranjos nos quais atores como municípios e sociedade civil têm um grande peso, em oposição a regiões com menor tradição, como a região norte, em que as ações ainda se restringem a atores estaduais. Assim, é interessante perceber o quanto as ações da 
região Sudeste privilegiam atores da sociedade civil e mesmo municípios, havendo uma menor prevalência de convênios com secretarias estaduais.

Outra inferência interessante, a partir da análise comparada entre as regiões sul, sudeste e norte, é perceber o quanto regiões com tradição em políticas de direitos humanos costumam implementar programas federais seguindo o modelo de outras áreas como a saúde e a assistência social, em que programas são formulados pela União para serem implementados por entes subnacionais. Diferentemente desse panorama, regiões com menor tradição costumam ter um maior protagonismo na formulação de políticas, como veremos, especialmente, em relação à região Norte.

\section{Região Sul}

Na região sul, há uma diversificação maior entre os órgãos concedentes, encontrando-se convênios financiados pela SEDH, SEPM, SEPPIR, Secretaria Nacional de Juventude, o Fundo Nacional da Criança e Adolescente, o Ministério da Educação, o Ministério do Esporte e o Ministério da Justiça, através de ações financiadas pela SENASP, pelo Departamento Penitenciário Nacional e pelo Fundo Nacional Antidrogas. As entidades concedentes têm distribuição equânime entre secretarias estaduais, prefeituras e entidades da sociedade civil.

As temáticas e ações objeto dos convênios também são mais diversificadas na região. Dentre os convênios voltados à promoção de direitos humanos do público prioritário da SEDH, destacam-se, também, ações para indígenas e quilombolas, idosos e mulheres vítimas de violência. As ações da SEPM também inovam ao enfocar direitos sexuais e reprodutivos, formação de promotoras legais populares, bem como a qualificação de servidoras penitenciárias para atuar no fortalecimento dos direitos humanos de mulheres presas, um vínculo entre políticas para as mulheres e políticas de segurança pública, tendo como objeto ações de direitos humanos.

No âmbito das políticas de direitos humanos envolvendo a área de segurança pública, destacam-se ações de capacitação em direitos humanos de policiais, guardas municipais e agentes de segurança, financiadas pela SENASP, e os tradicionais projetos de construção e ampliação de vagas prisionais, financiados pelo Departamento Penitenciário Nacional, desenvolvidos com secretarias estaduais de justiça ou de segurança. Em termos de implementação de políticas federais, estão o Plano Nacional de Políticas para as Mulheres, o Programa de Ações Integradas e Referenciais de Enfrentamento à Violência Sexual Infanto-Juvenil no Território Brasileiro, o PAIR, e a capacitação em direitos humanos de mulheres trabalhadoras rurais pertencentes aos Territórios de Cidadania, política do Ministério da Agricultura. Na área de segurança, há implementação de programas como o Mulheres da Paz. As ações do Fundo Nacional Antidrogas preveem a implantação de Conselhos Estaduais Antidrogas, ações de conscientização de famílias de usuários, ações de inclusão digital, através da atuação de Conselhos Tutelares e Conselhos Municipais de Políticas sobre Drogas. Assim como em outras regiões, a implementação de políticas federais costuma se dar pela atuação de secretarias estaduais.

É interessante perceber o quanto as ações da região Sul estão distribuídas entre atores da sociedade civil, secretarias estaduais e prefeituras. Em comparação com a região Sudeste, a implementação de programas federais ocorre em número reduzido na região Sul. Enquanto na região Sudeste há uma preocupação mais ampla com a segurança pública, na região sul as ações são mais diversificadas. Chama a atenção, também, que estão englobados sob a bandeira de "direitos humanos" convênios diversos, firmados com órgãos distintos dos encontrados nas outras regiões, ampliando o conceito de direitos humanos rumo à política 
social, muito embora o número de ações promovidas pela SEDH continue muito superior aos demais órgãos do governo federal.

Reproduzindo o que sustentamos em relação à região Sudeste, regiões com tradição na luta e na implementação de políticas de direitos humanos demonstram uma ampliação no foco das ações, permitindo um viés mais amplo do que tradicionalmente está englobado pela temática. Em termos de atores, regiões com desenvolvimento histórico na área também revelam uma maior diversificação, permitindo que a sociedade civil e os municípios sejam protagonistas dessas ações.

Veremos, agora, o quanto esse panorama se altera quando tomamos como objeto de análise a região Norte do país.

\section{Região Norte}

Nesta região, caracterizada por níveis mais baixos de desenvolvimento humano, verifica-se uma tendência mais estatalizada na promoção de ações de direitos humanos, uma vez que, praticamente, todos os convênios são promovidos por secretarias estaduais. Como órgãos concessores, novamente, estão a SEDH, a Secretaria Especial de Políticas para as MuI Iheres e o Ministério da Justiça, através do Deจे partamento Penitenciário Nacional e do Fundo ๙ Nacional Antidrogas.

a dicar o sub-registro civil (SEDH). Outro proণ blema objeto de ações é o tráfico de pessoas, $\vec{\Delta}$ especialmente mulheres (SEPM). As ações do Departamento Penitenciário Nacional também voltam-se a problemas locais, como a falta de vagas prisionais femininas.

Em sendo a maioria das ações desenvolvidas entre os órgãos federais e as secretarias estaduais, não havendo protagonismo da so- ciedade civil ou mesmo dos municípios, a região destaca-se, também, pela implementação de programas federais, sendo a região onde o modelo de coordenação do federalismo brasileiro é mais bem caracterizado. Ou seja, em regiões com pouca tradição de luta e de implementação de políticas de direitos humanos, ainda é muito reduzido o papel de outros atores que não os estados.

Esse mapeamento das regiões sul, sudeste e norte permite inferir sobre o padrão de desenvolvimento de políticas e programas de direitos humanos no Brasil, tendo em conta o desenho e a forma de exercício do federalismo brasileiro. Diferentemente de outros setores de políticas públicas, como a saúde e a assistência social, em que há uma clara coordenação das ações e políticas no governo federal, com o desenvolvimento de sistemas e políticas formuladas no âmbito da união e executados por estados, mas, principalmente, pelos municípios, a área de direitos humanos revela-se bastante esparsa.

Uma análise nacional dos convênios, tendo em conta os eixos prioritários de atuação da SEDH, SENASP, SPM e SEPPIR, somada à análise dos principais eixos de violação de direitos humanos, demonstram uma sobre representação de determinadas áreas, como crianças, adolescentes e deficientes, e uma carência de ações em outras, como políticas para idosos. Chama muito a atenção, também, a inexistência de programas relativos ao primeiro eixo da SEDH, cuja preocupação são as violações de direitos humanos de especial gravidade, com abrangência nacional, como chacinas, extermínio, assassinatos de pessoas ligadas à defesa dos direitos humanos, massacres, abusos praticados por operações das polícias.

Temas-chave de violação de direitos humanos ainda não são contemplados com ações promovidas pelos entes investigados. Outra característica das ações encontradas é a tendência ao financiamento de ações formuladas pelos entes subnacionais ou da sociedade civil, e a ainda reduzida implementação de polí- 
ticas federais, especialmente em regiões como a Sul, onde o protagonismo de municípios e sociedade civil é maior, distanciando-se do modelo federalista descrito acima. Outra constatação se refere à abrangência das ações tidas como de direitos humanos, constituindo um guarda-chuva sob o qual todo o tipo de ação pode se enquadrar.

Percebe-se, também, o quanto o modelo federalista, que concedeu autonomia aos municípios, tem diferentes formas de implementação, tendo-se em conta as regiões do país. Em primeiro lugar, é interessante perceber o quanto a temática e a promoção de políticas e programas de direitos humanos restringem-se à esfera estadual, aos estados, especialmente nas regiões de menores índices de desenvolvimento humano, enquanto nas regiões mais desenvolvidas encontra-se uma maior participação dos municípios nas ações de promoção a direitos humanos.

\section{CONSIDERAÇÕES FINAIS}

No processo de emergência da causa dos direitos humanos até a consolidação de políticas de Estado abrigadas sob essa perspectiva transcorreram três décadas. Nesse histórico, percebe-se a migração de um ativismo contestatório de estruturas autoritárias, ancorado, principalmente, no trabalho de advogados de perfil criminalista, que se empenhavam contra as prisões arbitrárias, com apoio nas organizações da Igreja Católica, para estruturas institucionais que promovem políticas de direitos humanos nas décadas de 90 e 2000. A "causa" diversifica-se com o restabelecimento dos direitos políticos e o fim do regime militar. Entram em cena outras espécies de militantismo, fortemente ancoradas na agenda de luta pela igualdade racial, na defesa dos direitos da infância e adolescência, direitos das mulheres e minorias sexuais e combate a violência policial.

Esse segundo momento se faz acompanhar da entrada em cena de outros padrões de militantismo, ancorados em parâmetros institucionais consolidados e na chegada ao poder político de ex-militantes da década de 70. A transformação dos direitos humanos em uma "política de Estado", com a concretização de políticas em diversos caminhos, acompanha um avanço de novos perfis de reivindicações em torno dessa causa, com maior articulação com as burocracias públicas nacionais e regionais.

Também fica evidenciada a relativa autonomia obtida pelas estruturas burocráticas, marcos legais e agentes que ocupam posições públicas nesse espaço em relação às oscilações eleitorais e às conjunturas dos governos. A continuidade das políticas específicas articuladas, assim como das iniciativas e movimentos ancorados fora da burocracia governamental são uma importante dimensão para a análise da consolidação política e simbólica dos direitos humanos no Brasil.

Recebido para publicação em 18 de novembro de 2013 Aceito em 30 de julho de 2014

\section{REFERÊNCIAS}

ADORNO, Sérgio. História e desventura: O $3^{\circ}$ Prograna Nacional de Direitos Humanos. Novos Estudos CEBRAP, n. 86 , março de 2010, p. 5-20.

ALMEIDA, Criméia Schmidt de; et al. Introdução. In: . Dossiê ditadura: mortos e desaparecidos políticos no Brasil (1964-1985). 2.ed. revista, ampliada e atualizada. São Paulo: Imprensa Oficial do Estado de São Paulo, 2009. p. 21-51.

AMNISTÍA INTERNACIONAL. Tortura. 2.ed. Madrid: Editorial Fundamentos, 1984.

ANDRADE, Paulo Fernando Carneiro de. A Igreja Católica e o Estado brasileiro. In: AVELAR, Lúcia; CINTRA, Antônio Octávio (Org.). Sistema político brasileiro: uma introdução. 2.ed. Rio de Janeiro: Konrad-Adenauer-Stiftung; São Paulo: Editora Unesp, 2007. p. 387-399.

AZEVEDO, Dermi. A Igreja Católica e seu papel político no Brasil. Estudos Avançados, v. 18, n. 52, 2004.

BALLESTRIN, Luciana. Direitos Humanos, Estado e Sociedade Civil nos governos de Fernando Henrique Cardoso (1994-2002). Teoria \& Sociedade (UFMG), v. 16 , n. 2, p. 10-33, 2008.

BENEVIDES, Maria Vitória de Mesquita. Comissão de Justiça e Paz em São Paulo. In: AVRITZER, Leonardo et al.(org.) Dimensóes políticas da justiça. Rio de Janeiro: Civilização Brasileira, 2013. 
BICUDO, Hélio. Direitos humanos e sua proteção. São Paulo: FTD, 1997.

CÂMARA DOS DEPUTADOS. Biografia de José Bonifácio Lafayette de Andrada. Disponível em: <http://www. camara.gov.br/internet/deputado/DepNovos Detalhe. asp?id=122787\&leg=45> . Acesso em 16 de junho de 2010 .

CANCIAN, Renato. Comissão Justiça e Paz de São Paulo: gênese e atuação política (1972-1985). São Carlos: EdUFSCar, 2005.

COMPARATO, Fábio Konder. A afirmação histórica dos Direitos Humanos. 6.ed., rev. e atual. São Paulo: Saraiva, 2008.

A responsabilidade do Estado brasileiro na questão dos desaparecidos durante o regime militar. In: TELES, Janaína (Org.). Mortos e desaparecidos políticos: reparação ou impunidade? 2.ed. São Paulo: Humanitas/ FFLCH/USP, 2001. p. 55-63.

DALLARI, Dalmo de Abreu. O renascer do direito: direito e vida social; aplicação do direito; direito e política. São Paulo: José Bushatsky Editor, 1976

ENGELMANN, Fabiano. Internacionalização e ativismo judicial: as causas coletivas. Lua Nova [online] n. 69, 2006.

Sociologia do campo jurídico: juristas e usos do direito. Porto Alegre: SAFE, 2006b.

GARLAND, Daniela C. Formation et reformulation d' une cause. Le cas des droit de l' homme au Chili, de la dictadure à la politiquee de réconciliation nationale. In: Politix: revue des sciences sociales du politique, n. 62. 2003

GENEVOIS, Margarida. Depoimento. In: ELOYSA, Branca (Org.). I Seminário do Grupo Tortura Nunca Mais. Petrópolis: Vozes, 1987. p. 140-144.

OLIVEIRA, Luciano. Direitos humanos e cultura política de esquerda. Lua Nova, n. 27, p. 149-165, 1992.

OSIEL, Mark Dialogue with dictators: judicial resistance in Argentina and Brazil. Law \& society Inquiry n. 20, 1995.
PADRÓS, Enrique Serra. Elementos constitutivos do Terror de Estado implementado pelas Ditaduras Civis-Militares de Segurança Nacional latino-americanas. In: PADRÓS, Enrique Serra (Org.). As ditaduras de Segurança Nacional: Brasil e Cone Sul. Porto Alegre: CORAG, 2006. p. 15-22.

PEREIRA, Anthony. Political (in)justice. Authoritarianism and the Rule of Law in Brazil, Chile and Argentina. Pittsburg: Un. of Pittsburgh, 2005.

PINHEIRO, Paulo Sérgio; MESQUITA NETO, Paulo de. Programa Nacional de Direitos Humanos: avaliação do primeiro ano e perspectivas. Estudos Avançados, n. 11 (30), 1997, p. 117-134.

SHERER-WARREN, Ilse. Movimentos sociais no Brasil contemporaneo. História: Debates e Tendencias, v. 7, n. 1, jan./jun. 2007, p. 9-21, publicada no $2^{\circ}$. Sem. 2008.

SUPREMO TRIBUNAL FEDERAL. Histórico do Supremo Tribunal Federal. Disponível em: $<$ http://www.stf.jus.br/portal/cms/verTexto. asp? servico $=$ sobreStfConhecaStfHistorico $>$. Acesso em 16 de junho de 2010 .

SUPREMO TRIBUNAL FEDERAL. Perfil biográfico dos ministros. Disponível em: http://www.stf.jus.br/portal/ ministro/ministro.asp?presidente $=\&$ periodo $=$ stf. Acesso em 16 de junho de 2010.

TRINDADE, Antônio Augusto Cançado. Dilemas e desafios da Proteção Internacional dos Direitos Humanos no limiar do século XXI. Revista Brasileira de Política Internacional, v. 40, n. 1, 1997, p. 167-177.

VECCHIOLI, Virginia. A luta pelo direito: engajamento militante profissionalização dos advogados na causa pelos direitos humanos na Argentina. Tese apresentada no PPG Antropologia Social Museu nacional-UFRJ. Rio de Janeiro, 2006.

VIEIRA, José Carlos. Democracia e Direitos Humanos no Brasil. São Paulo: Loyola, 2005 


\section{HUMAN RIGHTS CAUSES AND POLICIES IN BRAZIL}

\author{
Fabiano Engelmann \\ Lígia Mori Madeira
}

This study analyzes the emergence and consolidation of the human rights cause in Brazil over the last decades. The main argument is that the human rights movement emerged, as in other Latin American contexts, from the fight against totalitarian regimes, and was consolidated with institutional achievements after the re-democratization of the country. Analyzing the profile of the causes and trajectories of the main leaders of the movement in Brazil enables us to state that the human rights have become, over the 1990s, a "cause of the State". One of the strongest indicators of this transformation is the articulation between militant movements and the government bureaucracy, and the expansion of human rights programs across Brazil, especially in the South, Southeast and North.

Keywords: Brasil. Human Rights. Activism. Public Policies.

\section{LA CAUSE ET LES POLITIQUES DES DROITS DE L'HOMME AU BRÉSIL}

\author{
Fabiano Engelmann \\ Lígia Mori Madeira
}

Larticle se veut d'analyser l'apparition et la consolidation de la cause des droits de l'homme au Brésil au cours des dernières décennies. Le principal argument est que le mouvement des droits de l'homme surgit, comme dans d'autres contextes en Amérique latine, de la contestation du régime militaire autoritaire et qu'il s'est consolidé dans le cadre institutionnel après la re-démocratisation du pays. L'analyse du profil des causes et de la trajectoire des principaux leaders du mouvement au Brésil nous permet d'affirmer que les droits de l'homme se sont transformés au cours des années 90 en une "cause d'État". L'un des indicateurs les plus forts de cette transformation est le rapport entre les mouvements militants et la bureaucratie gouvernementale ainsi que l'expansion de programmes de défense des droits de l'homme, surtout dans les régions sud, sud-est et nord du pays.

Mots-clés: Brésil. Droits de l’Homme. Activisme. Politiques Publiques.

Fabiano Engelmann - Doutor em Ciência Política. Professor do Departamento e do Programa de PósGraduação em Ciência Política da Universidade Federal do Rio Grande do Sul-UFRGS. Bolsista de Produtividade do CNPq. Pesquisador do Núcleo de Estudos em Justiça e Poder Político da UFRGSNEJUP, Áreas de Pesquisa: Instituições Judiciais e Política, Elites e poder político e Sociologia Política.

Lígia Mori Madeira - Doutora em Sociologia. Professora adjunta do Departamento e do Programa de Pós-Graduação em Ciência Política da Universidade Federal do Rio Grande do Sul. Suas pesquisas enfocam os temas: instituições jurídicas comparadas, políticas sociais e desenvolvimento, violência, criminalidade e políticas públicas de segurança. Recentemente realizou estágio de pós-doutorado como Visiting Senior Fellow no Departamento de Politica Social da London School of Economics and Political Science. Bolsista da CAPES 


\section{ANEXO 1}

Trajetos secretários nacionais de direitos humanos

\begin{tabular}{|c|c|c|c|c|}
\hline Nome & $\begin{array}{c}\text { Período } \\
\text { na } \\
\text { SNDH } \\
\end{array}$ & Postos em organizações & Postos políticos & Informações gerais \\
\hline $\begin{array}{l}\text { José Gregori } \\
\text { (governo FHC) } \\
\text { Formação em } \\
\text { Direito }\end{array}$ & $\begin{array}{l}1997 \\
2000\end{array}$ & $\begin{array}{l}\text { 1964 e 1966: Conselheiro da Volkswagen do Brasil } \\
\text { 1972-1976: Conselho da Fundação Anchieta de Cultura } \\
\text { 1972-1982: Atuou como presidente da Comissão de } \\
\text { Justiça e Paz } \\
\text { 1982: Membro fundador da Comissão Teotônio Vilela de } \\
\text { Direitos Humanos } \\
\text { 1990-1995: Diretor secretário do Instituto de Integração } \\
\text { Latino Americana (ILAM) }\end{array}$ & $\begin{array}{l}\text { 1983-1986: Deputado Estadual (PSDB). } \\
\text { 1985-1986: Secretário de Estado da } \\
\text { Participação do Governo Montoro } \\
\text { 1987: Chefe de Gabinete do Ministério } \\
\text { de Reforma Agrária. } \\
\text { 1992: Chefe de Gabinete do Ministério } \\
\text { da Economia, Fazenda e Planejamento. } \\
\text { 2000 e 2002: foi ministro de Estado } \\
\text { da Justiça }\end{array}$ & $\begin{array}{l}\text { Sempre esteve próximo a setores da } \\
\text { esquerda, como a juventude católica, } \\
\text { mas nunca se filiou a nenhum partido. } \\
\text { Coordenador e coautor da Lei n. } \\
\text { 9140/95 (desaparecidos políticos). } \\
\end{array}$ \\
\hline $\begin{array}{l}\text { Paulo Sérgio } \\
\text { Pinheiro } \\
\text { (governo FHC) }\end{array}$ & $\begin{array}{l}2001 \\
2003\end{array}$ & $\begin{array}{l}\text { 1984: Membro da Comissão Justiça e Paz de São Paulo. } \\
\text { 1985-1989: Presidente da Comissão de Direitos Humanos, } \\
\text { Ordem dos Advogados do Brasil, OAB-São Paulo. } \\
\text { 1988: Membro da Comissão Federal de Direitos Humanos, } \\
\text { Ordem dos Advogados do Brasil, OAB. } \\
\text { 1997-2001: Vice-presidente e membro do conselho de } \\
\text { administração, do Instituto São Paulo Contra a Violência. } \\
\text { 1997-1998: Relator do Plano Estadual de São Paulo de } \\
\text { Direitos Humanos, o Brasil. } \\
\text { 1995-1996: Relator do Plano Nacional de Direitos Humanos } \\
\text { no Brasil: PNDH } \\
\text { 1997-1998: Presidente do grupo de Comissão da ONU sobre } \\
\text { Direitos Humanos } \\
\text { 1998: Membro da Subcomissão das Nações Unidas para a } \\
\text { promoção e proteção dos direitos humanos, Genebra } \\
\text { 2000-2002: Membro do Comitê de Organizaçães da } \\
\text { Sociedade Civil, do PNUD, em Nova York. } \\
\text { 2000: Consultor para o Relatório de Desenvolvimento } \\
\text { Humano das Nações Unidas. } \\
\text { 2000: Membro da Comissão Internacional de Inquérito da } \\
\text { ONU sobre suposta violaçáo de Direitos Humanos no Togo. } \\
\text { 2003: Relator do segundo Plano Nacional de Direitos } \\
\text { Humanos no Brasil: PNDH II } \\
\text { 2003: Perito independente nomeado pelo Secretário-Geral } \\
\text { da ONU para preparar um relatório mundial sobre a } \\
\text { violência contra crianças } \\
\text { 2003-2007: Membro da Comissão Interamericana de } \\
\text { Direitos Humanos, da Organização dos Estados Americanos } \\
\text { em Washington. }\end{array}$ & $\begin{array}{l}\text { 1983-1987: Especial Counsel [com o } \\
\text { status de Secretário de Estado] para o } \\
\text { governador do Estado de São Paulo. } \\
\text { 1999-2002: Membro do Conselho de } \\
\text { Administração da Comunidade } \\
\text { Solidária } \\
\\
\\
\end{array}$ & $\begin{array}{l}\text { Diplomata e jurista, é um professor } \\
\text { visitante na Brown University's Watson } \\
\text { Institute for International Studies. } \\
\text { Ocupou cargos acadêmicos } \\
\text { na Universidade de São Paulo, } \\
\text { Universidade de Oxford, e École } \\
\text { des Hautes Études en Sciences Sociales }\end{array}$ \\
\hline $\begin{array}{l}\text { Nilmário } \\
\text { Miranda } \\
\text { (governo Lula) } \\
\text { Formação em } \\
\text { jornalismo }\end{array}$ & $\begin{array}{l}2003 \\
2005\end{array}$ & $\begin{array}{l}1995 \text { e 1999: presidiu a Comissão de Direitos Humanos } \\
\text { 1999-2001: presidente do PT em Belo Horizonte } \\
\text { 2005-2007: presidente do PT mineiro. } \\
\text { 2008: Conselheiro do Editorial da Revista "Direitos } \\
\text { Humanos" da Secretaria Especial dos Direitos Humanos } \\
\text { da Presidência da República. }\end{array}$ & $\begin{array}{l}\text { 1986-1990: deputado estadual } \\
\text { por MG (PT) } \\
\text { 1990-2002: deputado federal por } \\
\text { três mandatos. (PT) } \\
\text { 2002 e 2006: foi a candidato ao } \\
\text { governo de Minas } \\
\text { 2006: candidato ao governo } \\
\text { de Minas Gerais }\end{array}$ & $\begin{array}{l}\text { "Preso e processado em 1968, forçado a } \\
\text { deixar a Faculdade de Ciências } \\
\text { Econômicas da UFMG, participou da } \\
\text { resistência clandestina à ditadura, até } \\
\text { ser novamente preso em São Paulo, 197 } \\
\text { Em } 1974 \text { voltou a Minas Gerais, preso, } \\
\text { para o presídio de Linhares em Juiz de } \\
\text { Fora. Após três anos e um mês como } \\
\text { prisioneiro político, voltou à UFMG, } \\
\text { graduando-se em jornalismo e com } \\
\text { mestrado em Ciência Política. Como } \\
\text { jornalista trabalhou no Jornal dos } \\
\text { Bairros, de 1976 a 1983; no Sindicato } \\
\text { dos Bancários em 1979; no Sindicato } \\
\text { dos Metalúrgicos de Betim em 1981 e } \\
\text { 1982. Filiou-se ao PT em 1980; dando } \\
\text { início em sua carreira política." }\end{array}$ \\
\hline $\begin{array}{l}\text { Mário } \\
\text { Mamede Filho } \\
\text { (governo Lula) } \\
\text { Formação em } \\
\text { Medicina }\end{array}$ & $\begin{array}{l}2005 \\
2006\end{array}$ & $\begin{array}{l}\text { Década de 90: presidiu a Comissão de Direitos Humanos } \\
\text { Década de 90: integrou a Comissão de Saúde e } \\
\text { Previdência Social. } \\
\text { Década de 90: vice-presidente da CPI (Comissão } \\
\text { Parlamentar de Inquérito) que investigou o tráfico de } \\
\text { crianças no Ceará. } \\
\text { 1993: membro da delegação brasileira na Conferência } \\
\text { Mundial de Direitos Humanos realizada em Viena. }\end{array}$ & $\begin{array}{l}\text { 1990-1994: deputado estadual } \\
\text { pelo Ceará (PT) } \\
\text { 1994-1998: deputado Estadual } \\
\text { pelo Ceará (PT) } \\
\text { 2001 a 2002: secretário de Saúde } \\
\text { do município de Horizonte. }\end{array}$ & $\begin{array}{l}\text { Ingressou no movimento sindical no } \\
\text { final da década de } 70 \text { atuando no } \\
\text { Movimento Nacional de Renovação } \\
\text { Médica-REME. } \\
\text { Na década de } 80 \text { teve importante } \\
\text { participação na fundação da Associação } \\
\text { dos Servidores do Detran. Ingressa na } \\
\text { carreira política na década de 1990, } \\
\text { engajando-se em temáticas relacionadas } \\
\text { aos Direitos Humanos. } \\
\end{array}$ \\
\hline $\begin{array}{l}\text { Paulo de } \\
\text { Tarso } \\
\text { Vannuchi } \\
\text { (governo Lula) } \\
\text { Formação em } \\
\text { Jornalismo }\end{array}$ & $\begin{array}{l}2006 \\
2011\end{array}$ & $\begin{array}{l}\text { 1977-1985: Cofundador e membro do Centro de } \\
\text { Educação Popular do Instituto Sedes Sapientiae. } \\
\text { 1980-1985: Trabalhou na equipe que realizou, sob } \\
\text { sigilo, o projeto de pesquisa "Brasil Nunca Mais". } \\
\text { 1981-2005: Assessoria política à Direção Nacional do PT } \\
\text { 2001-2005: Membro do Conselho de Redação da revista } \\
\text { "Teoria e Debates" }\end{array}$ & $\begin{array}{l}\text { 1983-2003: Assessor político } \\
\text { na Câmara Municipal de São Paulo. }\end{array}$ & $\begin{array}{l}\text { "Membro do Centro Acadêmico } \\
\text { Oswaldo Cruz, da Faculdade de } \\
\text { Medicina da USP, teve participação da } \\
\text { Militância política clandestina de } \\
\text { oposição ao regime militar da década de } \\
\text { 70. Desistiu da Faculdade de Medicina, } \\
\text { chegando a ser preso político em São } \\
\text { Paulo, um dos } 34 \text { signatários do amplo } \\
\text { dossiê entregue ao presidente nacional } \\
\text { da OAB, Caio Mário da Silva Pereira, } \\
\text { em } 23 \text { de outubro de 1975. Retornou a } \\
\text { USP, graduando-se em Jornalismo já em } \\
\text { 1980, Juntamente a sua ação no Partido } \\
\text { dos Trabalhadores" }\end{array}$ \\
\hline $\begin{array}{l}\text { Maria do } \\
\text { Rosário }\end{array}$ & $\begin{array}{l}2011 \\
\text { atual }\end{array}$ & $\begin{array}{l}\text { 1999-2000: Na Assembléia Legislativa, foi presidente da } \\
\text { Comissăo de Cidadania e Direitos Humanos. }\end{array}$ & $\begin{array}{l}\text { 1993-1999: Elegeu-se vereadora } \\
\text { de Porto Alegre. (PC do B) }\end{array}$ & $\begin{array}{l}\text { Oriunda dos movimentos comunitário e } \\
\text { estudantil e da militância sindical no }\end{array}$ \\
\hline
\end{tabular}

Fonte:Base de Dados do Projeto Intérpretes da Constituição: porta-vozes de políticas: juristas e ordem política brasileira, CNPq. 


\section{ANEXO II}

Revistas de direitos humanos brasileiras

\begin{tabular}{|c|c|c|c|c|}
\hline Revista & Editor & $\begin{array}{r}\text { Ano de } \\
\text { Fundaçâoo }\end{array}$ & N. de edições & Instituição Patrocinadora \\
\hline $\begin{array}{l}\text { Arquivos de Direitos } \\
\text { Humanos }\end{array}$ & $\begin{array}{l}\text { Antonio Celso Alves Pereira, } \\
\text { Ricardo Lobo Torres, Celso } \\
\text { Albuquerque Mello }\end{array}$ & $?$ & Última edição 2005 (?) & Editora RENOVAR \\
\hline $\begin{array}{l}\text { Direitos Humanos \& } \\
\text { Cidadania - Revista } \\
\text { Jurídica das Fipar }\end{array}$ & & $?$ & ? & $?$ \\
\hline $\begin{array}{l}\text { Revista Interdisciplinar de } \\
\text { Direitos Humanos }\end{array}$ & $\begin{array}{l}\text { ESTÁ RECEBENDO } \\
\text { ARTIGOS P } / 1^{\mathrm{a}} \text { EDIÇÃO }\end{array}$ & 2013 & - & $\begin{array}{l}\text { Observatório de Educação em Direitos Humanos } \\
\text { OEDH - UNESP }\end{array}$ \\
\hline $\begin{array}{l}\text { Revista Direitos Humanos } \\
\text { GAJOP }\end{array}$ & Valdênia Brito Monteiro & $1998(?)$ & 08 (2004), irregular & $\begin{array}{l}\text { Gajop (Gabinete de Assessoria Jurídica às Organizações } \\
\text { populares). }\end{array}$ \\
\hline $\begin{array}{l}\text { Revista do Instituto } \\
\text { Brasileiro de Direitos } \\
\text { Humanos }\end{array}$ & $\begin{array}{l}\text { Antônio Augusto Cançado } \\
\text { Trindade, } \\
\text { César Oliveira de Barros Leal }\end{array}$ & 1999 & $12(2012)$ & Instituto Brasileiro de Direitos Humanos \\
\hline $\begin{array}{l}\text { Revista Virtual Direitos } \\
\text { Humanos }\end{array}$ & $\begin{array}{l}\text { Agesandro da Costa Pereira } \\
\text { (presidente C.E.) }\end{array}$ & 2000 & $\begin{array}{l}\text { (?) IRREGULAR, último } \\
\text { número parece ser o 03, de } \\
2009\end{array}$ & $\begin{array}{l}\text { Conselho Federal da OAB - Comissão nacional de } \\
\text { Direitos Humanos }\end{array}$ \\
\hline $\begin{array}{l}\text { Revista Mestrado em Direito } \\
\text { Direitos Humanos } \\
\text { Fundamentais }\end{array}$ & Luiz Fernando da Costa e Silva & 2001 & $24(2012)$ & $\begin{array}{l}\text { Centro Universitário FIEO (Fundaçāo Instituto de } \\
\text { Ensino para Osasco). }\end{array}$ \\
\hline Revista Mais Humana & Nivia Valença Barros & 2003 & $09(2006)$ & $\begin{array}{l}\text { Universidade Federal Fluminense/Centro de Estudos } \\
\text { Sociais Aplicados/Escola de Serviço Social de } \\
\text { Niterói/Núcleo de Pesquisa Histórica sobre Proteção } \\
\text { Social. }\end{array}$ \\
\hline $\begin{array}{l}\text { SUR - Revista Internacional } \\
\text { de Direitos Humanos }\end{array}$ & $\begin{array}{l}\text { Pedro Paulo Poppovic, } \\
\text { Oscar Vilhena Vieira }\end{array}$ & 2004 & 17 & $\begin{array}{l}\text { Conectas Direitos Humanos, Rede Universitária de } \\
\text { Direitos Humanos }\end{array}$ \\
\hline $\begin{array}{l}\text { Revista Saúde e Direitos } \\
\text { Humanos }\end{array}$ & Nair Teles & 2004 & $07(2010)$ & $\begin{array}{l}\text { Ministério da Saúde Fundação Oswaldo Cruz Núcleo } \\
\text { de Estudos em Direitos Humanos e Saúde }\end{array}$ \\
\hline $\begin{array}{l}\text { Padê: Estudos em filosofia, } \\
\text { raça, gênero e direitos } \\
\text { humanos }\end{array}$ & Joelma Rodrigues & 2006 & 08 (encerrada) & UniCEUB - Centro Universitário de Brasília \\
\hline Revista Direitos Humanos & Paulo Vannuchi & 2008 & 05 & $\begin{array}{l}\text { Secretaria de Direitos Humanos da Presidência da } \\
\text { República }\end{array}$ \\
\hline $\begin{array}{l}\text { Revista Rompendo o } \\
\text { Silêncio }\end{array}$ & Paulo Pedron & 2011 & 01 & Instituto de Defesa dos Direitos Humanos \\
\hline $\begin{array}{l}\text { Revista de Direitos } \\
\text { Humanos }\end{array}$ & Orion Teixeira & 2012 & $\begin{array}{l}\text { 01, publicação irregular, } \\
\text { mala direta aos associados }\end{array}$ & Associação dos Magistrados Brasileiros \\
\hline $\begin{array}{l}\text { Revista direitos humanos e } \\
\text { democracia }\end{array}$ & Doglas Cesar Lucas & 2013 & 01 & $\begin{array}{l}\text { Programa de Pós-graduação Strictu Sensu em Direito da } \\
\text { Unijuí }\end{array}$ \\
\hline
\end{tabular}

Fonte:Base de Dados do Projeto Intérpretes da Constituição: porta-vozes de políticas: juristas e ordem política brasileira, CNPq. 
